\title{
О НЕКОТОРЫХ ВОПРОСАХ ПРОИЗВОДСТВА ОРГАНОМ ДОЗНАНИЯ НЕОТЛОЖНЫХ СЛЕДСТВЕННЫХ ДЕЙСТВИЙ
}

\begin{abstract}
Аннотация: Автор, на примере осуществления органами внутренних дел Российской Федерации оперативноразыскных мероприятий и следственных действий по уголовным делам о преступлениях, связанных с незаконным оборотом наркотиков, подробно исследует возможность оптимизации процедуры предварительного расследования. Сквозь призму идеи процессуальной экономии рассмотрены нормы уголовно-процессуального кодекса Российской Федерачии, регламентирующие деятельность органа дознания, связанную с производством проиессуальных действий до момента возбуждения, а также в рамках уголовного дела, по которому производство предварительного следствия обязательно. В прочессе исследования использовался общенаучный диалектический метод познания, частнонаучные методы: анализ и синтез, исторический метод. Исследована статистика, отражающая отдельные аспекты деятельности органов внутренних дел Российской Федерации в период с 2012 по 2014 год. Научная новизна проведенного исследования заключается в том, что автором изучено противоречие норм уголовно-процессуального кодекса Российской Федераџии, в соответствии с которыми орган дознания до момента возбуждения уголовного дела, предусматривающего производство предварительного следствия, лишен права производить любые следственные действия, даже при наличии необходимости обезопасить доказательственную информацию от возможной утраты или искажения.Автором акиентируется внимание на возможности оптимизации процедуры процессуального закрепления доказательственной информации, при условии дальнейшего совершенствования правовых норм, регламентирующих производство неотложных следственных действий. Вносятся и обосновываются авторские предложения по корректировке законодательного определения неотложных следственных действий, связанные с моментом и иелями их проведения.
\end{abstract}

Ключевые слова: Незаконный оборот наркотиков, первоначальный этап расследования, орган дознания, возбуждение уголовного дела, проиессуальная экономия, уголовное дело, неотложные следственные действия, судебная экспертиза, доказательственная информачия, органы внутренних дел.

Abstract: On the example of detective and investigative work by the branches of internal affairs of the Russian Federation on cases of illegal drug trade, the author gives a detail examination to the possibility of optimizing the procedure of preliminary investigation. Through the prism of the idea of procedural economy, the author reviews the norms of the criminal procedural code of the Russian Federation, which regulates the work of the investigative branch related to procedure up to the moment of indictment. Analysis is conducted on the statistics that reflect separate aspects of the work of the branches of internal affairs of the Russian Federation during the period of 2012-2014. The scientific novelty of this research consist in the fact that the author studied the contradiction of the norms of criminal procedural code of the Russian Federation, according to which the investigative branch up until the moment of indictment, which warrants preliminary investigation, lacks the right to conduct any investigative actions even if there is a need to secure pertinent information from possible loss or tempering. The author accents his attention on the possibility of optimizing the process of procedural recording of pertinent information should there be future improvements to the legal norms that regulate the procedure of high-priority investigative work.

Keywords: Internal affairs, pertinent information, forensic inquiry, criminal case, high-piority cases, procedural economy, indictment, investigative branch, initial stage of investigation, illegal drug trade.

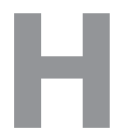

а протяжении длительного времени нормы отечественного уголовно-процессуального законодательства прямо или косвенно отражали стремление законодателя к осуществлению процедуры предварительного расследования в кратчайшие сроки.

Так, статья 266 Устава уголовного судопроизводства 1864 года содержала требование, обращенное к судебному следователю о необходимости «принимать своевременно меры, необходимые для собрания доказательств, и в особенности не допускать никакого промедления в обнаружении и сохранении таких следов и признаков преступления, которые могут изгладиться» [1]. Уголовно-процессуальные кодексы РСФСР 1922 и 1923 года предусматривали возможность принесения любыми заинтересованными участниками уголовного процесса «жалобы на медленность производства», допу- 
DOI: $10.7256 / 1811-9018.2015 .8 .16020$

При цитировании этой статьи сноска на dоі обязательна

\section{Право и политика 8 (188) 2015}

скаемую следователем, причем сроки принесения такой жалобы, наряду с жалобами на избрание меры пресечения и незаконные действия следователя, не были ограничены $[2,3]$. Статья 2 Уголовно-процессуального кодекса РСФСР 1960 года определяла первой из основных задач советского уголовного судопроизводства «быстрое и полное раскрытие преступлений».

Такое стремление законодателя, целями которого, в конечном счете, являются скорейшее восстановление нарушенных прав граждан, компенсация потерпевшим причиненного вреда и реализация права на разумный срок разбирательства дела и общепризнанного мировым сообществом права на скорый суд [4,5], в полной мере отвечает развитию действующих в уголовном процессе принципов гуманизма [6, с. 59] и процессуальной экономии.

Термин «процессуальная экономия» трактуется М.А. Гуревич как «необходимость наиболее полного и целесообразного использования установленных законом процессуальных средств и форм для правильного и быстрого разрешения дела» [7, с. 171].

По мнению П.Ф. Пашкевич «правосудие не должно тормозится необоснованной сложностью и неоправданной негибкостью процессуальных норм. Неоправданно сложная процессуальная форма там, где её можно заменить более простой, порождает медлительность бумажную волокиту, тормозит своевременную, наиболее эффективную охрану прав и законных интересов личности» [8, с. 41].

По мнению П.Я. Сокол быстрое расследование преступлений должно выступать в качестве одного из элементов процессуальной экономии [9, с.10].

М.П. Поляков и А.Ю. Смолин видят предназначение процессуальной экономии в экономичном (т. е. быстром, недорогом и простом) и при этом максимально возможном по своей полноте достижении целей уголовного судопроизводства [10, с. 68.].

Стремление законодателя к реализации принципа процессуальной экономии, а также к тому, чтобы обезопасить доказательственную информацию от возможной утраты или искажения, выразилось в наделении правоприменителя правом производить ряд следственных действий до возбуждения уголовного дела (в том числе в случаях, не терпящих отлагательства) $[11,12]$. Это осмотр места происшествия, документов и предметов (часть 2 статьи 176 УПК РФ), осмотр трупа (часть 4 статьи 178 УПК РФ), освидетельствование (часть 1 статьи 179 УПК РФ), судебная экспертиза (часть 4 статьи 195 УПК РФ), получение образцов для сравнительного исследования (часть 1 статьи 202 УПК РФ).
Органы предварительного расследования получили возможность производить следственные действия, целями которых на данном этапе служат, во-первых, получение и процессуальное закрепление информации, необходимой для решения вопроса о целесообразности возбуждения уголовного дела и начале уголовного преследования, и, во-вторых, обнаружение и фиксация следов преступления, а также доказательств, требующих незамедлительного закрепления, изъятия и исследования. При этом, явная экономия сроков производства, а также материальных и людских ресурсов заключается в том, что необходимая для расследования информация уже до возбуждения уголовного дела приобретает процессуальную форму и может быть процессуально закреплена до момента возможной утраты или искажения. Также по нашему мнению, законодатель, оговорив, что следственные действия, осуществляемые до возбуждения уголовного дела, проводятся в случаях, не терпящих отлагательств, фактически установил их принадлежность к неотложным.

Пункт 19 статьи 5 УПК РФ определяет неотложные следственные действия как действия, осуществляемые органом дознания после возбуждения уголовного дела, по которому производство предварительного следствия обязательно, в целях обнаружения и фиксации следов преступления, а также доказательств, требующих незамедлительного закрепления, изъятия и исследования.

Однако, орган дознания, получив информацию, требующую незамедлительного процессуального закрепления, имея возможность и в том числе, испытывая необходимость в производстве следственных действий, не наделен правом незамедлительно придать ей процессуальный статус доказательства до момента возбуждения уголовного дела. В соответствии с требованиями УПК РФ орган дознания до момента возбуждения уголовного дела, по которому предусмотрено производство предварительного следствия, лишен права производить любые следственные действия. Так, если следовать определению пункта 19 статьи 5 УПК РФ, то очевидно, что по неподследственному уголовному делу орган дознания вправе производить только неотложные следственные действия, производство которых, в свою очередь возможно только после возбуждения уголовного дела. Часть 5 статьи 152 УПК РФ также содержит указание на возможность производства дознавателем неотложных следственных действий только в рамках возбужденного уголовного дела.

По нашему мнению, такая позиция законодателя противоречит идее процессуальной экономии, так как ограничивает возможность органа дознания способ- 
DOI: $10.7256 / 1811-9018.2015 .8 .16020$

При цитировании этой статьи сноска на dоі обязательна

Закон и правопорядок

ствовать осуществлению процедуры предварительного расследования в кратчайшие сроки. С учетом вышеизложенного, считаем, что процессуальная деятельность органа дознания, связанная с производством процессуальных действий до момента возбуждения, а также в рамках уголовного дела, по которому производство предварительного следствия обязательно, нуждается в дополнительной законодательной регламентации.

Также, по нашему мнению, процессуальная деятельность органов дознания по производству неотложных следственных действий, при соответствующем изменении законодательства, может стать одной из эффективных форм проявления процессуальной экономии.

С целью обоснования предложений кратко рассмотрим в качестве примера осуществление подразделениями МВД России типичного комплекса оперативно-разыскных (далее - ОРМ) и процессуальных мероприятий (в нашем примере - судебной экспертизы) направленных на выявление и расследование преступлений, связанных с незаконным оборотом наркотиков. Выбор нами в качестве примера деятельности, связанной с расследованием преступлений данной категории обусловлен рядом причин. Во-первых, на протяжении нескольких лет отмечен устойчивый рост числа преступлений, связанных с незаконным оборотом наркотиков. Так, в 2012 году выявлено 219 тыс. преступлений, связанных с незаконным оборотом наркотиков. В 2013 году выявлено 231,5 тыс. преступлений данной категории. В 2014 году эта цифра возросла до 253,5 тыс. [13-15]. Во-вторых, ежегодно большая часть преступлений данной категории выявляется органами дознания органов внутренних дел. Так, в 2012 году 137,1 тыс. преступлений выявлено сотрудниками органов внутренних дел и 78 тысяч преступлений выявлено сотрудниками органов наркоконтроля [13], в 2013 году 147,3 тыс. преступлений выявлено сотрудниками органов внутренних дел и 78,8 тыс преступлений выявлено сотрудниками наркоконтроля [14]. В 2014 году 162,8 тыс. преступлений выявлено сотрудниками органов внутренних дел и 83,6 тыс. преступлений выявлено сотрудниками органов наркоконтроля [15]. В соответствии со статьей 150 УПК РФ по большинству из них предусмотрено проведение расследования в форме предварительного следствия. Часть этих преступлений отнесена к подследственности органов внутренних дел. Более того, по ряду преступлений данной категории, в соответствии с ч. 5 указанной статьи, предварительное следствие может производиться следователями органа, выявившего эти преступления, в том числе и следователями органов внутренних дел. В-третьих, в настоящее время органами внутренних дел Российской Федерации ежегодно предварительно расследуется приблизительно три четверти от всего массива зарегистрированных преступлений, включая связанные с незаконным оборотом наркотиков [13-15]. Дополнительно примем во внимание, что в соответствии с Указом Президента РФ на 110000 единиц сокращена предельная штатная численность органов внутренних дел [16]. В этих условиях видится неизбежным повышение нагрузки на все подразделения МВД России, осуществляющие профилактику, выявление и предварительное расследование преступлений, связанных с незаконным оборотом наркотиков. В связи с вышеизложенным считаем необходимым оптимизировать процедуру предварительного расследования, в том числе преступлений данной категории.

Преступления, связанные с незаконным оборотом наркотиков, посягают на здоровье населения и общественную нравственность, и перечислены в главе 25 Уголовного кодекса Российской Федерации (ст. $228-234)$.

Процесс расследования преступлений данной категории, отличается тем, что ошибки, допускаемые в процессе проведения ОРМ, осуществляемых до момента возбуждения уголовного дела, впоследствии, как правило, не могут быть исправлены на этапе предварительного расследования в ходе осуществления процессуальной деятельности. Более того, основным условием возбуждения уголовного дела, почти всегда является успешное проведение комплекса ОРМ, основными целями которого на данном этапе являются задержание лиц, осуществляющих преступную деятельность и изъятие наркотика. Для достижения этих целей оперативные сотрудники осуществляют ОРМ «проверочная закупка», основная задача которого - взятие с поличным лица, осуществляющего преступную деятельность и фиксация факта наличия при нем наркотика в количестве, явно превышающем необходимое для личного потребления.

Перед проведением проверочной закупки начальником органа, осуществляющего оперативно-разыскную деятельность (далее - ОРД) выносится соответствующее постановление. Впоследствии, когда решается вопрос о необходимости возбуждения уголовного дела, данный документ служебного характера рассекречивается и приобщается к материалам возбужденного уголовного дела [17].

После проведения комплекса ОРМ и задержания лиц, осуществляющих преступную деятельность, проводится доработка материалов проверки с целью последующей их передачи следователю для решения 
DOI: $10.7256 / 1811-9018.2015 .8 .16020$

При цитировании этой статьи сноска на доі обязательна

\section{Право и политика 8 (188) • 2015}

вопроса о возбуждении уголовного дела. При этом изъятые вещества направляются на исследование для установления факта наличия в них наркотиков. Результаты исследования, осуществленного сотрудником экспертно-криминалистического подразделения, на основании Наставления по организации экспертно-криминалистической деятельности в системе Министерства внутренних дел Российской Федерации, оформляются в виде справки оперативного исследования (справки о результатах исследования)[18].

Процессуальное значение этого документа представляется нам по меньшей мере спорным. Согласно позиции Конституционного Суда Российской Федерации, изложенной в определении от 04.02.1999 № 18-О, «результаты ОРМ являются не доказательствами, а лишь сведениями об источниках тех фактов, которые, будучи полученными с соблюдением требований Федерального закона «Об ОРД», могут стать доказательствами после закрепления их надлежащим процессуальным путем, то есть так, как это предписывается статьями 49 (часть 1) и 50 (часть 2) Конституции Российской Федерации [19]. Однако в судебной практике нетрудно отыскать примеры как исключения такого документа из числа доказательств [20], так и включения его в описательную часть приговора суда в качестве такового [21]. По нашему мнению, такая справка служит лишь формальным основанием для возбуждения следователем уголовного дела. Это подтверждается практикой, так, в рамках всех уголовных дел, изученных нами, следователем для доказательства вины подозреваемого назначалась судебная химическая экспертиза.

Кроме того, когда уголовное дело возбуждено и следователем назначено проведение судебной химической экспертизы, изъятые объекты, изученные ЭКП в рамках осуществления непроцессуальной деятельности, утрачивают свои первоначальные массу, объем, иные общие и специфические признаки. При этом может стать невозможным проведение как первичного (в связи с уничтожением объекта в ходе первоначального исследования), так и повторного процессуального криминалистического исследования (в связи с недостаточным количеством или утратой специфических качеств). Кроме того, справка оперативного исследования (справка о результатах исследования) может быть оспорена стороной защиты, как недостаточный повод для возбуждения уголовного дела, и осуществления задержания в порядке ст.91 УПК РФ, чем ставится под угрозу сама возможность осуществления уголовного преследования.

На следующем этапе, при осуществлении предварительного расследования в рамках возбужденного уголовного дела, следователем назначается судебная химическая экспертиза изъятых объектов. Её проводит как правило сотрудник того же экспертно-криминалистического подразделения, теперь на основании положений УПК РФ и Инструкции по организации производства судебных экспертиз в экспертно-криминалистических подразделениях органов внутренних дел Российской Федерации [22]. По её результатам эксперт составляет заключение, которое имеет доказательственное значение и по общему правилу принимается судом в качестве доказательства вины подсудимого.

Фактически силами двух сотрудников ЭКП при осуществлении ОРМ и процессуальных действий в рамках одного уголовного дела, осуществляется идентичная по своему содержанию деятельность, различающаяся процессуальным статусом производящего исследование лица и итогового заключения, которое он предоставляет. Следствием этого является двойная нагрузка, которую испытывают ЭКП. Кроме того, осуществление экспертных исследований объектов, изъятых в рамках осуществления оперативно-разыскной и процессуальной деятельности по уголовным делам, связанным с $\mathrm{HOH}$, влечет дополнительное расходование бюджетных средств, выделяемых для обеспечения целей деятельности экспертно-криминалистических подразделений МВД России.

По нашему мнению, осуществление судебной экспертизы в такой форме, при наличии практической возможности её назначения и проведения органом дознания до момента возбуждения уголовного дела, противоречит идее процессуальной экономии. Особенно, если имеется неотложная необходимость в проведении этого следственного действия.

Для устранения обозначенных проблем предлагаем исключить из законодательного определения неотложных следственных действий указание на обязательность возбуждения уголовного дела для их производства и дополнительно отразить в законодательном определении неотложных следственных действий ещё одну цель их производства - «получение оснований для решения вопроса о начале уголовного преследования». Это изменение позволит использовать результаты производства данных следственных действий как в качестве исходной информации, необходимой для решения вопроса о начале уголовного преследования, так и в качестве готового доказательства по уголовному делу, возбужденному впоследствии. Кроме того, такое законодательное определение позволит органу дознания при выявлении любого преступления производить при необходимости в качестве неотложных те следственные действия, производство которых в данный момент разрешено законодателем до возбуждения уголовного дела. 


\section{Библиография:}

1. Устав уголовного судопроизводства от 20 ноября 1864 года [Электронный ресурс]: CПC ГAPAHT. - URL: http:// base.garant.ru/57791498/17/\#block_20200\#ixzz3MmFAuEbq (дата обращения 21.06.2015).

2. Ст. 216 и ст. 219 УПК РСФСР 1922 года, утверждённого постановлением ВЦИК от 25.05.1922. [Электронный peсурс]: СПС КонсультантПлюс. - URL: www.consultant.ru/document/cons_doc_ESU_4006/ (дата обращения 21.02.2015);

3. Ст. 215 УПК РСФСР 1923 года, утверждённого постановлением ВЦИК от от 15.02.1923. [Электронный ресурс]: СПС КонсультантПлюс. - URL: www.consultant.ru/document/cons_doc_ESU_3551/(дата обращения 21.06.2015).

4. Пункт «с» части 3 статьи 14 Международного Пакта от 16.12 .1966 «О гражданских и политических правах» // Бюллетень Верховного Суда РФ. - 1994. - №12.

5. Пункт 3 статьи 5 Конвенции о защите прав человека и основных свобод (Заключена в г. Риме 04.11.1950) // Бюллетень международных договоров. - 2001. - №3.

6. Прокофьева С.М. Концепция гуманизации уголовного судопроизводства. Монография / Под общ. ред. В.П. Сальникова. СПб.: Санкт-Петербургский университет МВД России. 2002. - 448 с.

7. Гуревич М. А. Принципы советского гражданско-процессуального права// Труды Всесоюзного юридического заочного института. - .М., 1965. Т.3.

8. Пашкевич П. Ф. Процессуальный закон и эффективность уголовного судопроизводства. - М., $1984 .-176$ с.

9. Сокол П.Я. Процессуальные гарантии быстроты предварительного расследования. - Автореф. дисс...канд. юрид. Наук. - М., 1990.

10. Поляков М.П., Смолин А.Ю. Принцип процессуальной экономии в уголовном судопроизводстве. Монография / Н. Новгород.: Нижегородская академия МВД России. 2011. - 152 с.

11. П. 21 и П. 22 ст. 1 Федерального закона от 02.12.2008 №226-Ф3 «О внесении изменений в Уголовнопроцессуальный кодекс Российской Федерации»// Собрание законодательства РФ. -08.12.2008. - № 49. - Ст. 5724.

12. П. 19 и п. 20 ст. 2 Федерального закона от 04.03.2013 № 23-Ф3 «О внесении изменений в статьи 62 и 303 Уголовного кодекса Российской Федерации и Уголовно-процессуальный кодекс Российской Федерации»// Собрание законодательства РФ. -04.03.2013. - № 9. - Ст. 875.

13. Состояние преступности в Российской Федерации - январь-декабрь 2012 года [Электронный ресурс]: официальный сайт МВД России. - URL: https://mvd.ru/reports/item/804701/(дата обращения 21.02.2015).

14. Состояние преступности в Российской Федерации - январь-декабрь 2013 года [Электронный ресурс]: официальный сайт МВД России. - URL: https://mvd.ru/reports/item/1609734/(дата обращения 21.02.2015);

15. Состояние преступности в Российской Федерации - январь-декабрь 2014 года [Электронный ресурс]: официальный сайт МВД России. - URL: https://mvd.ru/reports/item/2994866/(дата обращения 21.02.2015).

16. Указ Президента РФ от 13.07.2015 № 356 «О внесении изменения в Указ Президента Российской Федерации от 5 мая 2014 г. № 300 «О некоторых вопросах Министерства внутренних дел Российской Федерации»//Собрание законодательства РФ. -20.07.2015. - № 29 (часть II). - Ст. 4472.

17. Статья 11 Федерального закона от 12.08.1995 N 144-Ф3 (ред. от 29.06.2015) «Об оперативно-розыскной деятельности». [Электронный ресурс]: СПС КонсультантПлюс. - URL: http:/base.consultant.ru/cons/cgi/online. cgi?req=doc;base=LAW;n=181943 (дата обращения 25.07.2015).

18. Об утверждении Наставления по организации экспертно-криминалистической деятельности в системе МВД России: Приказ МВД России от 11 января 2009 № 7. [Электронный ресурc]: CПC КонсультантПлюс. - URL: http://base.consultant.ru/cons/cgi/online.cgi?req=doc;base=EXP;n=451495 (дата обращения 25.07.2015).

19. Определение Конституционного Суда РФ от 04.02.1999 № 18-О «По жалобе граждан М.Б. Никольской и М.И. Сапронова на нарушение их конституционных прав отдельными положениями Федерального закона «Об оперативно-розыскной деятельности»// Вестник Конституционного Суда РФ. - 1999. - №3.

20. Постановление ФАС Северо-Западного округа от 23.12.2009 по делу № А56-33508/2009 ИФНС неправомерно отказала ООО в возмещении НДС, сославшись на подписание счетов-фактур неустановленным лицом, поскольку справки экспертно-криминалистического центра ГУВД о результатах оперативного исследования, проведенного в рамках ОРМ, не могут быть признаны надлежащими доказательствами по данному делу.

21. Приговор Невского районного суда Санкт-Петербурга в суда по делу № 1-780/11 [Электронный ресурс]: официальный сайт УФСКН по Санкт-Петербургу и Ленинградской области. - URL: http://www.gnk.spb.ru/ prigovor2012/13.htm (дата обращения 23.07.2015).

22. Вопросы организации производства судебных экспертиз в экспертно-криминалистических подразделениях органов внутренних дел Российской Федерации: Приказ МВД России от 29 июня 2005 № 511 (в ред. от 15 октября 2012). [Электронный ресурс]: СПС КонсультантПлюс. - URL: http://base.consultant.ru/cons/cgi/online. cgi? req=doc;base=LAW;n=141831 (дата обращения 20.07.2015).

23. В. Н. Григорьев Начало уголовного производства: система сдержек и противовесов // Союз криминалистов и криминологов. - 2013. - 2. - С. 17 - 21. 
DOI: $10.7256 / 1811-9018.2015 .8 .16020$

При цитировании этой статьи сноска на доі обязательна

\section{Право и политика $8(188) \cdot 2015$}

\section{References (transliterated):}

1. Prokof'eva S.M. Kontseptsiya gumanizatsii ugolovnogo sudoproizvodstva. Monografiya / Pod obshch. red. V.P. Sal'nikova. SPb.: Sankt-Peterburgskii universitet MVD Rossii. 2002. - 448 s.

2. Gurevich M. A. Printsipy sovetskogo grazhdansko-protsessual'nogo prava// Trudy Vsesoyuznogo yuridicheskogo zaochnogo instituta. - .M., 1965. T.3.

3. Pashkevich P. F. Protsessual'nyi zakon i effektivnost' ugolovnogo sudoproizvodstva. - M., 1984. - 176 c.

4. Sokol P.Ya. Protsessual'nye garantii bystroty predvaritel'nogo rassledovaniya. - Avtoref. diss...kand. yurid. Nauk. - M., 1990.

5. Polyakov M.P., Smolin A.Yu. Printsip protsessual'noi ekonomii v ugolovnom sudoproizvodstve. Monografiya / N. Novgorod.: Nizhegorodskaya akademiya MVD Rossii. 2011. - 152 s.

6. V. N. Grigor'ev Nachalo ugolovnogo proizvodstva: sistema sderzhek i protivovesov // Soyuz kriminalistov i kriminologov. 2013. - 2. - C. $17-21$. 